\title{
Destructive Diversity, Inflationary Convergence and the Inflation Criterion : The Way to EMU Reconsidered
}

\author{
Michael Berlemann \\ Dresden University of Technology CESifo
}

\begin{abstract}
Since the signing of the Maastricht Treaty, there has been an intensive discussion whether the convergence criteria incorporated into the contract were appropriate to prepare the EU-member-countries for European Monetary Union. We argue that at least inflationary convergence was not a necessary precondition for EMU. This paper aims at analyzing the effects of the inflation criterion with regard to its possible influence on welfare of the EU-member-states during the transitional phase (stage II). It is shown that the inflation criterion can be interpreted as a component of an incentive compatible contract; insofar it has contributed to a decrease in inflation bias during stage II of EMU but played no important role with respect to stage III.
\end{abstract}

- JEL classification: E58, F15, F33

- Keywords: Convergence criteria, Time consistency, Incentive compatible Contracts, EMU

\section{Introduction}

The process of monetary integration in Europe has a long history. When the Treaty of Rome was signed in 1957 the member states of the European Economic Community were already aware of the necessity of supplementing the economic

\footnotetext{
*Corresponding address: Michael Berlemann, Ifo Institute for Economic Research, Branch Dresden, Einsteinstrasse 3, D-01069 Dresden, Germany. Phone: 0049+351+2647617, fax: 0049+351+2647620, Email: Berlemann@ifo.de @ 2006-Center for International Economics, Sejong Institution, All Rights Reserved.
} 
process of integration with a monetary union. However, it took another 13 years before the idea of monetary union found expression in the so-called Werner Plan for economic and monetary union. According to this plan monetary and fiscal cooperation were equally important objectives; moreover European Monetary Union (EMU) should serve as a catalyst for the ultimate goal of a political union. However, the collapse of the Bretton Woods agreement on international monetary cooperation and the 1970's oil price crises were serious drawbacks on the way to EMU. With the introduction of the European Monetary System (EMS) the EEC countries tried to reenforce the process of European integration but it took again a decade before the suggestions of the Delors Report finally led to the decision to start the process of monetary integration. On 7th February 1992 the heads of government of the EU member states signed the Maastricht Treaty thereby accepting the so-called step-by-step-plan toward realizing EMU. After a transitional phase of 7 years, during which the EU member countries had to qualify for taking part, EMU started with 11 countries $^{1}$ on 1 st January 1999. With the formal introduction of the common currency on 1st January 2002 the process of monetary integration for the core countries formally succeeded.

It is not surprising that the discussions among politicians, economists and the public on European Monetary Integration during the long process of monetary integration in Europe were quite controversial. At the beginning the discussion focussed primarily on the questions what are the costs and benefits from EMU and which countries should take part in it. When the plans for realizing EMU were getting concrete in the aftermath of the Delors Report the discussion was extended to transition scenarios toward monetary union. In this paper we will reconsider the debate on the adequate transition scenarios toward EMU in the light of experiences of the last decade. We argue that inflationary convergence, as demanded by the inflation criterion of the Maastricht Treaty, was not a necessary precondition of a successful EMU. However, we show that - given the decision to have a transitional phase toward EMU - the inflation criterion was useful nevertheless. This is due to the fact that the inflation criterion remarkably decreased the incentive of national central banks to use the last years of responsibility for monetary policy to organize surprise inflation in order to stimulate real activity.

The paper is organized as follows: The basic model applied in this paper is outlined in the second section. In the third section we describe the situation the

${ }^{1}$ Only Greece failed to fulfill the convergence criteria in 1998 but was allowed to take part 2 years later. 
national central banks faced before signing the Maastricht Treaty. In the fourth section we outline EMU on stage III and explain why inflationary convergence was not a necessary precondition for a successful monetary union. Section 5 deals with the hypothetical scenario of an EMU without convergence criteria. Building up on these considerations we show in the sixth section that the inflation criterion was in fact welfare-improving. We also present some empirical results underlining our theoretical arguments. The paper closes with a short summary of the main results.

\section{The Model}

The large number of contributions to the debate on EMU made use of various different theoretical models. We suggest that the widely accepted standard model of time inconsistency of monetary policy developed by Barro and Gordon $(1983 a, b)$ provides an excellent framework for our purposes of analyzing the process and different scenarios of monetary integration. According to the BarroGordon-model, monetary policy is interpreted as an interactive policy problem between the monetary authority and trade unions. The model employs a Lucas supply function according to which output decreases below its natural level provided that the trade unions underestimated the rate of inflation:

$$
y_{t}=\pi_{t}-\pi_{t}^{e},
$$

where $y_{t}$ is output at time $t, \pi$ is the inflation rate and $\pi^{e}$ is expected inflation. For simplicity, we assume the natural level of output to be zero and the rate of inflation to be under perfect control of the monetary authority. ${ }^{2}$ Trade unions try to anticipate the expected rate of inflation during collective wage negotiations as precisely as possible because they have to decide on the optimal labor supply. Furthermore, it is postulated that the trade unions' intertemporal loss function is symmetric as far as expectation errors are concerned

$$
L_{t}^{T U}=\sum_{t=1}^{T}\left(\frac{1}{1+r}\right)^{t-1} \cdot\left(\pi_{t}-\pi_{t}^{e}\right)^{2},
$$

\footnotetext{
${ }^{2}$ Both assumptions can be relaxed without violating our line of arguments.
} 
where $r$ is the discount rate that applies between periods $\mathrm{t}$ and $\mathrm{t}+1 . T$ defines the time horizon of the interaction problem. For the moment we assume the government to be responsible for monetary policy. ${ }^{3}$ The government's intertemporal loss function, which is assumed to be identical to the social loss function, is given by

$$
L_{t}^{G}=\sum_{t=1}^{T}\left(\frac{1}{1+r}\right)^{t-1} \cdot\left(\frac{1}{2} \cdot \pi_{t}^{2}+\frac{1}{2} \cdot \beta \cdot\left(y_{t}-y^{*}\right)^{2}\right), \quad \beta>0,
$$

where $\beta$ is a measure for the relative degree of importance the government attaches to the ambitious output-target $y^{*}>0 .{ }^{4}$ For the moment we assume all loss functions, all parameters and the model to be common knowledge. The following sequential structure is assumed for the interaction process between the government and the trade unions: at the beginning of every single period the government announces a certain rate of inflation $\pi_{t}^{a}$. Afterwards, trade unions form their inflation expectations and anticipate them during the wage negotiations. Finally, the government determines the rate of inflation in order to minimize its expected intertemporal loss.

The first best solution of the described game, taking into account the loss function of the government only, would require $\pi_{t}=0$ and $y_{t}=y^{*}$. The second best solution can be calculated by minimizing the governmental loss function with respect to $\pi_{t}$ and $\pi_{t}^{e}$, taking into account equation 1 and the trade unions' rational expectations (following directly from minimizing the trade unions' loss function with respect to $\left.\pi_{t}^{e}\right)$. Second best requires $\pi_{t}=0$ and $\pi_{t}^{e}=E\left[\pi_{t}\right]=0$, thus implying $y_{t}=0$.

While the first and second best solution base on the assumption of the existence of a benevolent social planner fixing both, inflation and inflationary expectations, the Nash solution of the game describes the policy choices of the government and the trade unions in equilibrium provided both players act individually rational. The Nash solution of the one-shot version of the above described model (i.e. $T=1$ ) can be derived by considering the sequential structure of the game. When deciding on

\footnotetext{
${ }^{3}$ This assumption is consistent with the existence of a completely government dependent central bank. Later on we will consider the case of more independent central banks.

${ }^{4}$ Again for simplicity, we assume the optimal inflation rate to be zero. This assumption can be relaxed without effect on the argument.
} 
the inflation rate, the government already knows the trade unions' inflationary expectations. This ends up in the well known inflationary bias $\pi_{t}=\pi_{t}^{e}=\beta \cdot y^{*}$ and $y_{i}=0$. Thus, the government fails to realize the second best solution.

\section{The Situation before Maastricht}

The situation the EU member countries faced before the Maastricht Treaty was signed, can be best described as an infinitely repeated version of the above presented monetary policy game (i.e. $T=\infty$ ). Every period the government in country $i$ can select between one of the two following strategies: either it sticks to its announcement or it attempts to cheat the trade unions by deviating from the announced rate of inflation. The best cheating strategy is the Nash solution

$$
\pi_{t, i}=\beta_{t} \cdot y_{i}^{*}
$$

Following Barro and Gordon (1983b), the trade unions' reaction on the government's behavior can be described by some sort of trigger mechanism, e.g.

$$
\pi_{t, i}^{e}= \begin{cases}\pi_{t, i}^{a}, & \text { if } \pi_{t-1, i}^{a}=\pi_{t-1, i} \\ \beta \cdot y_{i}^{*}, & \text { else }\end{cases}
$$

This mechanism implies that in period $t$ the Pareto inferior solution of an anticipated rate of inflation causing no real effects is the result of cheating in period $t$-1. In period $t+1$ trade unions face the initial problem again owing to the fact that the government's reputation has been restored. ${ }^{5}$

The problem to be solved by the government is to compare the expected gains and losses from violating the announced rate of inflation after the trade unions have formed their expectations.

Barro and Gordon (1983b) have shown that there is a range of credible inflation announcements and the lowest credible announcement is a weighted average of the second best and the Nash solution of the one-shot game

\footnotetext{
${ }^{5}$ It should be noted, that the above presented one-period trigger mechanism is somewhat arbitrary and that it is in particular not the result of some kind of optimization problem. However, similar solutions apply for trigger mechanisms with longer punishment periods. Generally the incentive for the government to cheat gets weaker the longer the punishment period of the trade unions is. In line with Barro and Gordon $(1983 \mathrm{a}, \mathrm{b})$ we suppose a finite punishment period to be realistic.
} 


$$
\pi_{i}^{a, \min }=\frac{\beta_{i} \cdot\left(1-\beta_{i}\right) \cdot y_{i}^{*}-\frac{\beta_{i} \cdot y_{i}^{*}}{1+r_{i}}}{1-\beta_{i}+\frac{1}{1+r_{i}}}
$$

The discount factor $r_{i}$ plays a decisive role herein. The lowest credible inflation rate gets the closer to the inflationary bias $\beta_{i} \cdot y_{i}^{*}$ of the one-shot game, the higher the monetary authority's discount factor is and vice versa. Although there is a set of possible Nash equilibria, it is obvious that the government has incentives to choose the lowest credible inflation rate in order to avoid excessive inflation without real effects. Nevertheless the inflationary bias will not vanish completely as long as country $i$ 's discount rate $r_{i}$ is positive and the government has an ambitious output target.

Different from our initial assumption, all EU-member-states had delegated monetary policy to a more or less independent central bank. Independence is a necessary but not sufficient condition for a central bank to be able to serve as a credible commitment device. The executive council of a completely dependent central bank is not able to resist any political pressure and therefore will act as to minimize the government's loss function in order not to be dismissed. Independent central banks can be more successful in this matter. But even if a central bank is totally independent from the government there is no guarantee that the inflationary bias will vanish. If the central banker shares the government's preferences, the situation will end up in the same inflation bias as before although the central bank is independent from the government. An important question in this context is why a good number of countries decided to have an independent central bank, nevertheless.

The answer for that question was given by Rogoff (1985). He showed that a "conservative" central banker, who puts less relative weight on the ambitious output target, will be able to commit himself credibly to a lower inflation rate than the government will be able to. ${ }^{6}$ A necessary precondition for a conservative central banker to be successful in lowering the inflationary bias is - as demonstrated earlier - at least some degree of central bank independence. Thus, we can interpret the establishment of a central bank with at least a minimum of independence as an attempt at installing a weight-conservative monetary authority. That is why we argue in the following, as is often done in literature (Walsh (2000), p. 377), that the

\footnotetext{
${ }^{6}$ It should be noted that a weight-conservative central banker fails to reach the second best solution in models with stochastic supply shocks, indeed. Nevertheless, a third best solution can be realized.
} 
degree of central bank independence is closely related to weight-conservativity in the sense that a higher degree of central bank independence implies more weightconservativity (i.e. $\beta_{i} \rightarrow 0$ ) and thus a lower inflationary bias.

However, there is one basic problem with the solution of delegating monetary policy to a weight-conservative central banker. As claimed by McCallum (1995), delegation does not resolve the dynamic inconsistency, it merely reallocates it to the relation between government and central bank. If the government decides on delegation by discretion, it has an incentive to fire the central banker as soon as the trade unions have anticipated their expectations in the wage negotiations and to appoint a new central banker with the government's preferences to be able to realize the second best solution. The trade unions anticipate this behavior and the inflationary bias will remain. This problem can be solved by incurring the government some "overruling" or "reappointment costs" (that might be immaterial). As Lohmann (1992) showed, the problem can be solved completely under the assumption that the reappointment cost is an instrument variable of the government. If the reappointment cost is exogenously given, as in Jensen (1997), the resulting inflationary bias can be reduced but not completely eliminated. ${ }^{7}$ In the following we assume that the reappointment costs for the government are sufficiently high to secure that the central banker is not dismissed. ${ }^{8}$

According to these considerations, the situation the EU-member-states faced before signing the Maastricht Treaty can be characterized as follows: principally all EU-member-state faced a time inconsistency problem of monetary policy resulting in inflationary biases. Because of the infinite horizon of the above described interaction problem reputation effects enabled the national monetary authorities to commit credibly to lower inflation than it would have been possible in a one-shot game. The inflationary bias was further lowered by delegating monetary policy to more or less independent (and thus more or less weight-conservative) central banks. Because of the fact that none of the EU-member-states had a completely independent central bank (not even Germany), the bias was not removed completely. Thus, we should find a stable relationship between central bank independence and inflation in the EU-member-states before the transitional phase

\footnotetext{
${ }^{7}$ Jensen (1997) also shows that the set of discount factors, securing that an announced inflation rate is credible, shrinks when costs increase.

${ }^{8}$ This does not mean, that the government has no influence on monetary policy in the case of an at least partially dependent central bank. Only a completely independent central banker is assumed to attach a weight of $\beta_{i}=0$ to the ambitious output target and is thus able to realize the second best solution.
} 
to EMU.

To check whether the presented model and the related assumptions provide a useful framework for analyzing the transitional period toward EMU we run a simple empirical test. We therefore analyze inflation rates in the EU-membercountries, which tried to qualify for EMU, ${ }^{9}$ before the transitional phase. During the time before the Maastricht Treaty was signed we should find a positive correlation between the degree of central bank independence on the one hand and the average inflation rate on the other. The literature offers several concepts of measuring central bank independence. In the following we will concentrate on two of the most advanced methods propsed by Grilli et al. (1991) and Cukierman (1992).

Grilli, Masciandaro and Tabellini (1991) distinguish between two dimensions of central bank independence: political and economic independence. Political independence is understood as the central bank's ability to decide on the final goals of monetary policy on its own. The index of political independence is constructed on the basis of features like the relationship between central bank and government in the formulation of monetary policy, procedures for appointing the board of the central bank and formal responsibilities of the central bank with respect to monetary policy. Economic independence includes the central bank's ability to choose between different monetary policy instruments. The degree of economic independence is determined by using criteria like the government's credit facilities or the responsibility for the supervision of bank regulation. ${ }^{10}$

Cukierman (1992) developed three different indices of central bank independence. While the so called "turnover Index" is not appropriate for well-developed industrial countries, a second one does only consider 9 of 15 EU-member-states. Therefore, we focus on the third index which is constructed solely on the basis of the existing legal sources in the relevant country. Compared to other concepts of the empirical measurement of central bank independence, Cukierman considers a large number of features to construct a reliable index. In contrast to the most other approaches he puts different weights on the single features to take their relative importance into account. ${ }^{11}$

\footnotetext{
${ }^{9}$ We excluded Great Britain and Denmark from the sample because these countries did not sign the Maastricht Treaty without modifications (compare again the earlier expositions on this point). Sweden was also excluded because it was not long enough member of EU to be allowed to take part in EMU in 1999.

${ }^{10}$ The central banks of Luxemburg and Finland have not been considered by Grilli et al. (1991).

${ }^{11}$ Greece and Portugal have not been considered by Cukierman (1992).
} 
In the following the Grilli- as well as the Cukierman-index of central bank independence are used to test the null hypotheses. Our pre-transitional sample period starts shortly after the oil-price-crisis in 1978 and ends in $1991 .{ }^{12}$

Starting with the Grilli-index, we run the following linear multiple regression (OLS method):

$$
\bar{\pi}_{i}=c+\gamma_{1} \cdot I_{i}^{p}+\gamma_{2} \cdot I_{i}^{e}+\varepsilon_{i},
$$

where $\bar{\pi}$ is the average inflation rate over the sample period, $c$ is a constant, $\gamma_{1}$ and $\gamma_{2}$ are the regression coefficients for the two dimensions of central bank independence, $i$ is a country index and $\varepsilon$ is the unexplained residual. The earlier presented theoretical considerations predict a negative sign for $\gamma_{1}$ and $\gamma_{2}$ for the pretransitional period. The results are reported in Table 1.

Table 1. Multiple regression results under the Grilli-index:

\begin{tabular}{cccccc}
\hline Period & $\mathrm{c}$ & $\gamma_{1}$ & $\gamma_{2}$ & Observations & $R^{2}$ \\
\hline \multirow{2}{*}{$1978-1991$} & 19,62 & $-1,34$ & $-1,49$ & 10 & 0,76 \\
& $(7,73)$ & $(-1,93)$ & $(-2,41)$ & & \\
\hline
\end{tabular}

For the pre-transitional period we find significantly negative coefficients for both regressors, political and economic independence. The estimated regression function explains 76 per cent of the observed average inflation rates.

For the Cukierman-index we estimate the following regression function:

$$
\bar{\pi}_{i}=c+\gamma \cdot I_{i}^{c}+\varepsilon_{i}
$$

The results for the Cukierman-index are reported in Table 2.

Table 2. Regression results under the Cukierman-index

\begin{tabular}{ccccc}
\hline Period & $\mathrm{c}$ & $\gamma$ & Observations & $R^{2}$ \\
\hline \multirow{2}{*}{$1978-1991$} & 11,88 & $-13,72$ & 10 & \multirow{2}{*}{0,61} \\
& $(7,05)$ & $(-3,57)$ & & \\
\hline
\end{tabular}

\footnotetext{
${ }^{12}$ It might be argued that the period between 1988 and 1991 should be excluded from the analysis because of the intense discussions about the most promising way to EMU at that time. It is possible that at least some EU-member-states have already begun to change their policy to qualify for EMU during that time. We also tested the shorter period 1978-1988 and got only slightly differing results.
} 
The results are similar to those under consideration of the Grilli-index. Again, we find a significantly negative coefficient for central bank independence for the pretransitional phase. The regression explains about 60 per cent of the observed variance in the inflation rates.

Summing up, we interpret the results of the (admittedly quite simple) empirical test as supportive to the applicability of the presented theoretical framework to analyze the process of European monetary integration.

\section{European Monetary Union on Stage III and Implications for Possible Transitional Scenarios}

As it was pointed out earlier, in this paper we are primarily interested in judging the adequacy of the transitional stage toward EMU (i.e. stage II). However, we will first have a closer look at stage III of EMU since the optimal transition path obviously depends on how the desired scenario for stage III of EMU looks like.

In the Maastricht Treaty it was stipulated that the newly established European Central Bank (ECB) should take over the responsibility for monetary policy from the national central banks of those countries successful in fulfilling the convergence criteria at the beginning of stage III. Even if the national central banks still have some influence on ECB's monetary policy via the membership of the presidents in the ECB-council, the influence of each single member state is obviously somewhat limited. Principally, the situation ECB faced at the beginning of stage III is similar to the situation of the national central banks before the onset of the process of monetary integration. Thus, it is now the newly established ECB which takes part in the monetary policy game described in the previous section. Because of the infinite time horizon of the interaction problem the equilibrium inflation rate is again:

$$
\pi^{a, \min }=\frac{\beta_{E C B} \cdot\left(1-\beta_{E C B}\right) \cdot y_{E C B}^{*}-\frac{\beta_{E C B} \cdot y_{E C B}^{*}}{1+{ }^{r} E C B}}{1-\beta_{E C B}+\frac{1}{1+r_{E C B}}},
$$

where $\beta_{E C B}$ is the weight, ECB attaches to the output target. Since the inflationary bias on stage III of EMU depends strongly on $\beta_{E C B}$ we have to care about the important question which factors determine $\beta_{E C B}$.

To answer this question let us first assume the heads of government of the EU- 
Figure 1. Average CPI inflation in EU countries 1978-1991.

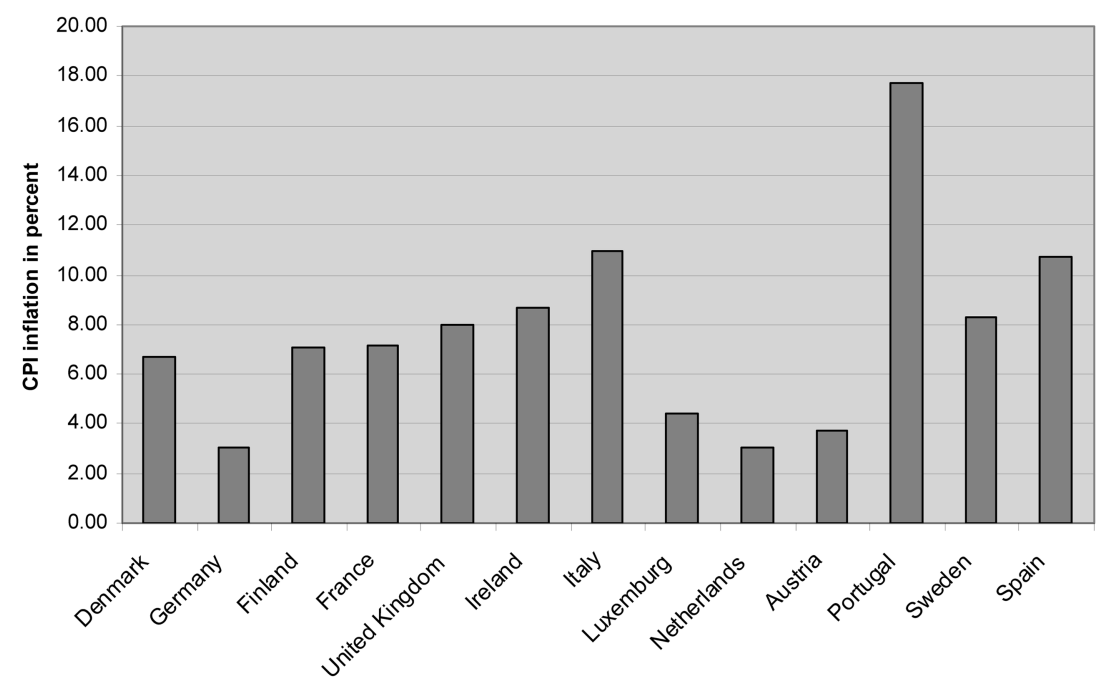

member countries had agreed to set up a completely government dependent central bank sharing the preferences of the median voter of the EU-member-countries. Due to the fact that the European Union has no common government yet, key political decisions are currently jointly made by the heads of governments of the EUmember-countries which themselves can be assumed to represent the referring countries' median voters. In that case, ECB's weight on the output target would have been somesort of average of the national weights (DeGrauwe (1996), pp. 67).

Figure 1 reveals that the average inflation rates during 1978-1991 in the EUmember-countries differed considerably, thereby indicating differences in national preferences on the goals of stable prices and high employment as well as in the institutional settings. ${ }^{13}$ Thus, the inflationary bias on stage III of EMU would have been higher than the one in the stable countries and lower than in the less stable countries before EMU. ${ }^{14}$ Countries with a strong preference for price stability

\footnotetext{
${ }^{13}$ Remarkable differences could also be observed with respect to several other macroeconomic variables like nominal interest rates, public debt, real wages or per-capita income.

${ }^{14} \mathrm{~A}$ similar conclusion results from the view that monetary union is some form of collusion between central bankers. By reducing competition between European central banks in providing stable currencies the threat of exchange rate devaluations decreases thereby leading to a lower degree of price stability in a monetary union. However, since ECB is not a monopolist in providing currency the threat resulting from currency devaluations does not diminish completely (see Vaubel (1994) and Wagner (2001) for a discussion of this aspect.)
} 
which had nothing to gain in terms of price stability from EMU (like e.g. Germany or the Netherlands) obviously would have had a low degree of interest in such a monetary union. To motivate the inflation averse EU member countries to take part in EMU some contractual arrangement was necessary to convince them that the newly established ECB will follow a tight monetary policy in order to guarantee price stability.

The Delors report dealt with the problem of heterogenous preferences toward price stability by favoring a gradual process toward EMU. ${ }^{15}$ The proponents of this strategy, the so-called "gradualists", argue that at least in the beginning of stage III of EMU the monetary policy game, in which ECB is engaged, differs in one important respect from the interaction problems the national central banks faced before EMU. While the market participants (as e.g. trade unions) knew the relative preference of their national central banks quite well there is obviously a larger degree of uncertainty concerning the preferences of the newly established ECB. According to this view a quick change in the monetary regime might cause deep crises in those countries with formerly high inflation rates since market participants need time to adjust their expectations to the new environment. This "destructive diversity" 16 would therefore not allow a common restrictive monetary policy for the whole $\mathrm{E}(\mathrm{M}) \mathrm{U}$ area. Given the inflation history of countries like Portugal or Greece a simple announcement to follow an inflation averse politics would be incredible. Inflationary expectations would remain high as long as the monetary authority would not have proved to stick to its announcement to run a more restrictive monetary policy. Thus, a transitional stage would be necessary to lower both, inflation and inflationary expectations before monetary unification could succeed. A formal model underlining this argument has been provided by Winkler (1999). His model employs the idea that national central banks used stage II of EMU to signal a change in preferences toward price stability via choosing lower inflation rates. Thus, a transitional stage appears as a necessary precondition for monetary unification enabling the EU-member-countries to demonstrate their “deeply rooted stability culture" (Winkler (1999), p. 41).

The gradual approach toward EMU as proposed by the Delors Report was finally

\footnotetext{
${ }^{15}$ The costs and benefits of gradualism as well as of a shock therapy toward EMU are discussed in Willms (1996).

${ }^{16}$ This term was used by Heikensten (2000).

${ }^{17}$ For a detailed description of the background of the Maastricht negotiations see Artis (1994).
} 
adopted in the Maastricht Treaty. ${ }^{17}$ To ensure the necessary degree of convergence, a number of convergence criteria were set up which had to be fulfilled by those countries willing to enter the final stage of EMU. ${ }^{18}$ At least two of the convergence criteria, namely the inflation and the interest rate criterion, directly focus on guaranteeing inflationary convergence. While the inflation criterion demands converging inflation rates, the interest rate criterion is primarily focussing on credibility aspects of monetary policy. 19 However, one might argue that the remaining criteria also focus on guaranteeing price stability. The exchange rate criterion requires that a country should have been in the 'normal' bands of the European Exchange Rate Mechanism (ERM) for at least two years. Since diverging inflation rates create pressures on the exchange rate this criterion again restricts domestic monetary policy. The two fiscal criteria specify reference values for the ratio of the budget deficit to GDP and for the ratio of outstanding government debt to GDP (3 respectively 60 percent) which should principally not be exceeded. Different from the other criteria the fiscal criteria still hold after the introduction of the common currency. The fiscal criteria proved to be the most controversial ones. They obviously restrict government debt financing and thereby contribute to prevent that EMU countries accumulate such a large public debt that ECB gets under pressure to inflate away the burden of public debt. ${ }^{20}$

However, there are reasonable arguments suggesting that inflationary convergence was not a necessary precondition of monetary unification within Europe. At least as soon as the Maastricht Treaty was signed the national central banks were aware of the fact that they will loose their responsibility for national monetary policy. From a political economy perspective one might suspect that the central bank administrations had low incentives to force the process of monetary integration. However, even if the national central banks would have had an interest in building up a reputation for ECB it is hard to imagine how they should have succeeded herein. Reputation is the result of not-disappointed expectations in a specific institutional environment (Wagner (1995), p. 139). Reputation can therefore hardly be transferred from national central banks to a new institution like ECB (Issing (1997), p. 184). Thus, even a good performance of the national central banks during the

\footnotetext{
${ }^{18}$ For a discussion of the Maastricht criteria compare e.g. Welfens (1996a).

${ }^{19}$ As long as long-term interest rates remain high market participants obviously do not believe in disinflation policies.

${ }^{20}$ Artis (1994), p. 361.
} 
transitional stage in fighting inflation would have been no guarantee that the newly established ECB performs equally well in this task. DeGrauwe (1993, p. 657) expounds in this respect: "The past history of these currencies becomes irrelevant". But even if the national central banks' reputation in fighting inflation could have been transferred to the newly established ECB it is highly questionable in how far decreasing inflation rates in the EU member countries during the transitional stage could be interpreted as signals of deeply rooted stability cultures. In order to take part in EMU the EU-member-countries had to accept the rules, i.e. to fulfill the convergence criteria. But if a country decides to make attempts at fulfilling the criteria this does not necessarily mean that it changes its preferences by attaching a higher relative weight to the goal of price stability than before. An observed change in monetary policy is much more likely to be the result of high preferences of taking part in EMU, f.ex. because of expected extra surpluses from enhanced trade. ${ }^{21}$

It is worth noting that the degree of convergence did not increase by much during the transitional stage of EMU. In figure 2 we show the degree of convergence of CPI inflation in the EU member states in the period of 1978-1999 (measured by the standard deviation of inflation). ${ }^{22}$ Even if the inflation rates converged considerably over the two centuries, the degree of convergence in early 1992, i.e. the time when

Figure 2. Inflationary convergence in EU member countries 1978-1999.

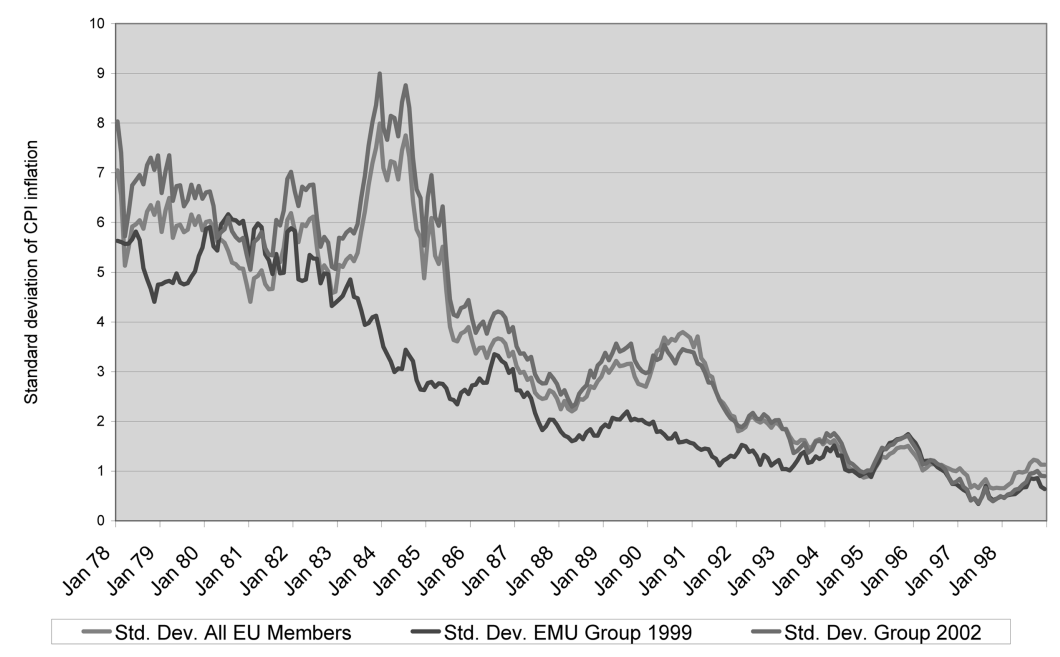

\footnotetext{
${ }^{21}$ We will provide a formal analysis of this aspect in section 6 .

${ }^{22}$ The figures base on data from IMF, International Financial Statistics.
} 
the Maastricht Treaty was signed, was already comparatively high. Especially the degree of convergence within the group of countries that took part in EMU by 1999 was almost as high as in the beginning of EMU in January 1999. Thus, even if inflationary convergence would have been a necessary precondition of EMU, the transitional stage did not increase the level of convergence by much.

One possible strategy of forming a monetary union is to credibly fix the exchange rate between the EMU countries, like it was intended earlier in the European Exchange Rate Mechanism (ERM). Modern monetary theory interprets the introduction of fixed exchange rate regimes as attempts to import the credibility of foreign central banks in fighting inflation from abroad. ${ }^{23}$ While this attempt to import a low foreign inflation rate does not resolve but merely reallocate the time inconsistency problem from the field of monetary policy to exchange rate policy, the advantage of this strategy is that the central bank's willingness to stick to its announcement to hold the exchange rate constant can easily and quickly be observed. Thus, a gradual and in terms of rising unemployment costly process of disinflation can typically be avoided. ${ }^{24}$ However, von Hagen and Fratianni (1996) argue that exchange rate pegs are likely to be inefficient to form a monetary union of several countries since the central bank in the anchor country is primarily concerned with domestic business cycles. It therefore might neglect the external effects of monetary policy - what has proven to be case during the ERM Crisis of 1992 when the German Bundesbank insisted on its restrictive monetary policy although most other ERM countries suffered severe recessions. The proposal to adopt one of the stable European currencies (as f.ex. the German Mark) as common currency and to transfer the responsibility for monetary policy to the referring central bank (see e.g. Welfens (1996b), p. 264) is problematic because of the same reasons. Moreover it was infeasible due to issues of national pride. Last but not least, all the attempts to import credibility by an exchange rate peg finally depend on the anchor country's success in solving its own time inconsistency problem of monetary policy.

In the light of these deficiencies of the importing-credibility-approach the EUmember-countries chose an alternative way of solving the time inconsistency problem of monetary policy which is in fact very similar to the solution adopted in Germany

\footnotetext{
${ }^{23}$ See e.g. Giavazzi and Pagano (1988).

${ }^{24}$ Historical experiences with currency pegs show that these attempts often allow to restore credibility quickly. Argentina and Bulgaria are good examples how a country can quickly import price stability without suffering a severe recession via a currency board arrangement. See e.g. Berlemann and Nenovsky (2004).
} 
before 1999. While it was impossible to import the German Bundesbank's credibility in fighting inflation directly, considerable attempts were made to copy its institutional structure as well as its monetary policy strategy ${ }^{25}$ (at least partially) and to locate ECB in Germany. Since the countries with the lowest long-term average inflation rates were afraid of increasing inflation in the aftermath of the introduction of a common currency they insisted on a statute granting a high degree of central bank independence to ECB. In fact, ECB is judged to be even more independent than the German Bundesbank (see Artis (1994), p. 363-364, or Wagner (1995), p. 139). However, as we argued earlier in this paper, independence itself is no guarantee for low inflation. The low inflation countries therefore also insisted on appointing an extremely weight-conservative central banker as first president of ECB. The intense and highly controversial discussion between the heads of government of the EU member states on the eve of stage III on the question, who should be the first president of ECB, showed that this decision had been of great importance to the EU-member-countries. Besides the expectation that the president of ECB will have a major influence on monetary policy decisions the appointment of a central banker, who already proved to be hard-nosed in fighting inflation, could be interpreted as an attempt to import the credibility of at least one central bank. The highly controversial debate on thechoice of the first ECB president underlines that several EU-member-states had serious doubts in how far the low inflation rates in the eve of EMU were credible signals of a high preference toward the goal of stable prices.

Summing up, we conclude that inflationary convergence was not a necessary precondition of EMU. There are serious doubts whether low inflation rates in the eve of EMU were credible signals of deeply rooted preferences for price stability; even if the central banks of former high inflation countries would have gained some credibility by decreasing inflation rates it is unclear how this credibility should have been transferred to ECB. The fact that the EU member countries finally decided to establish an extremely independent ECB and to appoint a central banker who already proved his weight-conservativeness (in the terminology of Rogoff (1985)) indicates the suspicions of the former low inflation countries that the true preferences toward price stability were still quite heterogenous. However, this institutional setup did not demand for a transitional stage of 5 or even 7 years.

However, this does not necessarily mean that the convergence criteria

\footnotetext{
${ }^{25}$ While the German Bundesbank officially announced to follow a pure monetary targeting strategy we agree with von Hagen (1995) that the strategy was quite similar to an inflation targeting strategy.
} 
incorporated into the Maastricht Treaty were completely useless or unnecessary. On the contrary, we will argue in the following that - given the decision for a gradual process toward $\mathrm{EMU}^{26}$ - the nominal criteria were necessary to guarantee price stability in the EU member countries during the transitional phase toward EMU. Thus, we argue from a positive perspective in the following.

\section{The Effects of a Maastricht Treaty without Convergence Criteria}

In order to examine the effects of the convergence criteria for the EU-memberstates it is useful to analyze first what would have happened had these criteria not been incorporated into the MT. The following expositions base upon the assumption that in December 1991 the EU-member-states had agreed to introduce a common currency in a fixed number of participating states on 1st January 1999. This would have meant that the national central banks of the participating states would have hand over responsibility for monetary policy to ECB on $31 \mathrm{st}$ December 1998. This imaginary treaty is further called "unconditional Maastricht Treaty" (UMT).

The effects caused by an UMT can be illustrated by applying the model described in section 2. The situation national central banks would have been in can no longer be regarded as an infinitely repeated game. Had the UMT been signed in 1992 as well, there would have been only a few years left in which national central banks would have been responsible for monetary policy. Thus, the interaction problem between national central banks and trade unions would have changed dramatically: the dimension of infiniteness would have dissolved and we would have dealt with a finite horizon game.

Finite horizon games can be solved using the technique of backward induction. Let us therefore first analyze the situation arising from the UMT in 1998. National central banks are aware that they have to make their final decisions on national monetary policy in that year. Naturally this fact strongly influences that final

\footnotetext{
${ }^{26}$ Though we argue that a transitional stage was not necessary to generate a higher degree of inflationary convergence we do not principally deny the necessity of the transitional stage per se. One might argue that a transitional stage was necessary because of technical restrictions (like e.g. the establishment of an European Central Bank, harmonization of the national payment systems or explanation of the new currency system to the public) or some other economic reasoning than the necessity of inflationary convergence. However, we will not try to summarize nor continue this discussion here (see e.g. De Grauwe (1992), pp. 130-141 or Willms (1996) for extensive discussions of this aspect).
} 
decision. The minimization problem a national central bank faces in such circumstances is much simpler since the national central banks only minimize the loss of this final period in 1998:

$$
L_{1998}^{C B}=\frac{1}{2} \cdot \pi_{1998}^{2}+\frac{1}{2} \cdot \beta \cdot\left(Y_{1998}-Y^{*}\right)^{2} .
$$

This minimizing-problem is solved, as mentioned above, by choosing

$$
\pi_{1998}=\beta \cdot Y^{*}
$$

This means that national central banks would always choose a rate of inflation higher than the lowest credible one without the UMT (compare with equation (6)). Trade unions are aware of a central bank's temptation to try to cheat in this last period 1998. Therefore, they expect exactly the rate of inflation from equation (10). Thus, an UMT would have caused a Pareto inferior situation compared to the case without Maastricht Treaty in period 1998.

A similar situation would have evolved under the UMT in 1997. All arties involved would have recognized that national central banks attempt to realize the cheating solution from equation (10) in the final period. However, from the central banks' point of view, it would not pay off to improve their reputation by not trying to cheat in 1997. This can be foreseen by the trade unions so that in both 1997 and 1998 the same Pareto inferior solution would have evolved. The same applies to all previous periods. Thus, an unconditional Maastricht Treaty would have meant a severe blow to welfare in the transitional phase.

\section{The Inflation Criterion as a Component of an Incentive Compatible Contract}

In contrast to the preceding section we now assume that the EU-member-states have agreed to sign a conditional contract in Maastricht. Similar to Walsh (1995) we examine in how far the MT, especially the inflation criterion, can be judged to be incentive compatible with regard to avoiding an inflationary bias during stage II of EMU.

\section{A. The inflation criterion}

The MT stipulates that only those EU-member-states fulfilling four convergence 
criteria are entitled to take part in European Monetary Union (EMU). As explained earlier, we will concentrate our analysis on one of these criteria: the so-called "inflation criterion". This criterion requires that the annual change in consumers' prices must be strictly within a range of 1.5 per cent above the average rate of inflation in the Union's three countries with the stablest prices. For stage II of EMU it was agreed to check whether the member states were fulfilling the convergence criteria or not from 1996 onwards. Had a majority of EU-member-states fulfilled the convergence criteria in 1996, a common currency would have been introduced as early as $1^{\text {st }}$ January, 1997. Of course only those countries fulfilling the convergence criteria would have been allowed to take part in monetary union. The next check had been due in 1998. However, from 1998 on it would not have been necessary that there were a majority of states fulfilling the criteria. Any one member-state fulfilling the criteria would have taken part in EMU automatically in 1999. ${ }^{27}$ The MT does not only require to fulfil the inflation criterion in the last period but demands for continuity in fighting inflation. The formulation of the inflation criterion is far away from being exact and can be interpreted in different ways. However, countries that would have fulfilled the inflation criterion only in the last period would have almost certainly not been allowed to take part in EMU. $^{28}$

The MT is different from the kind of contracts discussed in the section before, because the treaty has not been signed by the government and the monetary authority but only by the governments of the EU-member-states. Yet it seems to be appropriate to assume that the contract is relevant with regard to the objectives of both, a dependent and an independent central bank, at least because of the fact that the inflation criterion demands nothing else from the national central banks than the legislature in most countries: a monetary policy emphasizing primarily stable prices.

The inflation criterion does not embody a monetary policy rule. As mentioned above, keeping to the inflation criterion was obligatory for those member states who were interested in participating in EMU. In case of a federal government deciding to create a rate of inflation deviating from the target range (defined by the

\footnotetext{
${ }^{27}$ Only Britain and Denmark insisted on being entitled to hold another referendum on EMU in order to let the electorate decide, even if Britain and Denmark should have fulfilled the criteria.

${ }^{28}$ Nevertheless, it would have been preferable to have a more exact definition of the inflation criterion concerning the time dimension.
} 
inflation criterion), for whatever reasons, one could not speak of a violation of a rule but rather of a lack of interest in taking part in EMU.

An incentive compatible contract implies a modification of the monetary authority's loss function. This modification is meant to induce a change of the central bank's behaviour in a way that creating inflation is no optimal strategy, not even after the trade unions built their expectations. However, the process of "producing" inflation must be followed by sanctions of some kind. This can be achieved by a successrelated salary or a credible threat to dismiss the central banker. The MT also possesses a sanction that punishes the creation of an excessive rate of inflation with exclusion from EMU (provided that participating in monetary union would indeed be advantageous for the country of interest).

In order to be able to judge whether participating in EMU would be advantageous for a particular country, one must weigh up benefit and costs (see DeGrauwe's survey (1992)). However, it is of little significance whether introducing EMU is in fact an advantage or disadvantage for a particular country because it is the monetary authority's conviction alone which is of importance. In the following we assume, for the sake of simplicity, that EMU generates a constant additional welfare effect of $u_{i}$ for country $i$ each period. Thus, the discounted future welfare effect for country in the starting year $\tau$ of EMU (1999) is

$$
U_{i, \tau}=\sum_{t=\tau}^{\infty}\left(\frac{1}{1+r}\right)^{t-\tau} \cdot u_{i}=\frac{1+r}{r} \cdot u_{i} .
$$

We assume that all $U_{i}$ 's as well as the loss functions of the EU-member-states are common knowledge.

Moreover, we have to take into account that the MT's inflation criterion is somewhat different from the type of contract presented in the preceding section. The inflation criterion is formulated as a relative performance contract. From a theoretical point of view the criterion would have been fulfilled if all candidates had a high inflation rate of 10 percent. Thus, it is questionable whether the inflation criterion really had a restrictive effect on inflation. To be able to answer this question, we will first consider a somewhat simplified version of the inflation criterion by only using the inflation rate of the most stable country $(j)$ as a criterion. Thus, each country $i$ that fulfills the restriction

$$
\pi_{t, i} \leq \pi_{t, j}+x
$$


will be allowed to take part in EMU. The variable $x \geq 0$ describes by how much the inflation rate in country $i$ may exceed the one in the most stable country, the reference country $j$, without loosing the right to take part in EMU.

\section{B. Optimal behaviour when joining EMU}

For each country $i$ we can establish a Lagrange-function that describes the central bank's loss provided that the country takes part in EMU:

$$
\begin{gathered}
L_{t, i}^{C B}=\frac{1}{2} \cdot \pi_{t, i}^{2}+\frac{1}{2} \cdot \beta_{i} \cdot\left(\pi_{t, i}-\pi_{t, i}^{e}-Y_{i}^{*}\right)^{2} \\
-\left(\frac{1}{1+r}\right)^{\tau-t} \cdot U_{i, \tau}+\lambda_{i} \cdot\left(\pi_{t, i}-\pi_{t, j}-x\right) .
\end{gathered}
$$

The Kuhn-Tucker-conditions of this minimization problem are:

$$
\begin{gathered}
\frac{\partial L_{t, i}^{C B}}{\partial \pi_{t, i}}=\pi_{t, i}+\beta_{i} \cdot\left(\pi_{t, i}-\pi_{t, i}^{e}-Y_{i}^{*}\right)+\lambda_{i} \geq 0 \\
\frac{\partial L_{t, i}^{C B}}{\partial \lambda_{i}}=\pi_{t, i}-\pi_{t, j}-x \leq 0 \\
\lambda_{i} \cdot \frac{\partial L_{t, i}^{C B}}{\partial \lambda_{i}}=\lambda_{i} \cdot\left(\pi_{t, i}-\pi_{t, j}-x\right)=0
\end{gathered}
$$

In order to derive the inflation rate which country $i$ chooses when entering EMU we have to distinguish between the two cases: $\lambda_{i}=0$, i.e. condition 11 is not restrictive, and $\lambda_{i} \neq 0$, i.e. condition 11 is restrictive.

For the case of $\lambda_{i}=0$ condition 15 is obviously fulfilled. Thus, according to condition 13 country $i$ chooses the inflation rate

$$
\pi_{t, i}=\beta_{i} \cdot Y_{i}^{*}
$$

For the most stable country $j$ we know condition 11 to be not restrictive, i.e. $\lambda_{j}=0$. Thus, country $j$ 's central bank has no incentive to alter its decision on inflation compared to the case without MT:

$$
\pi_{t, j}=\beta_{j} \cdot Y_{j}^{*}
$$


Similarly, all countries $k$ fulfilling condition 11 even without the Maastricht Treaty (we will call these countries "intermediate" countries in the following) will stick to their prior inflation rates

$$
\pi_{t, k}=\beta_{k} \cdot Y_{k}^{*}
$$

For the case $\lambda_{i} \neq 0$ we know $\pi_{t, l}-\pi_{t, j}-x=0$ to hold true from condition 15 . Thus, we can calculate the inflation rate of country $l$ as

$$
\pi_{t, l}=\pi_{t, j}+x=\beta_{j} \cdot Y_{j}^{*}+x
$$

While these considerations allow us to determine which inflation rate a country will choose when joining EMU we did not consider under which conditions a country will join EMU. We will turn to this aspect in the following subsection.

\section{The decision of the most "stable" country}

To judge whether a country $i$ will take part in EMU we have to compare the loss under participation with the loss resulting when choosing not to take part. From the above analysis we know that the most stable country will choose the same inflation rate as without the MT in the first case: $\pi_{t, i}=\beta_{i} \cdot Y_{i}^{*}$. If country $i$ chooses not to take part it will have to increase its inflation rate by $x$ above the rate of the stablest country $(j)$ that takes part in EMU at the minimum. ${ }^{29}$ Thus, country $i$ will take part in EMU if

$$
\begin{gathered}
\frac{1}{2} \cdot\left(\beta_{i} \cdot Y_{i}^{*}\right)^{2}+\frac{1}{2} \cdot \beta_{i} \cdot Y_{i}^{* 2}-\left(\frac{1}{1+r}\right)^{\tau-t} \cdot U_{i, \tau}<\frac{1}{2} \cdot \beta_{i} \cdot Y_{i}^{* 2}+\frac{1}{2} \cdot\left(\beta_{j} \cdot Y_{j}^{*}+x\right)^{2} \\
\Leftrightarrow\left(\frac{1}{1+r}\right)^{\tau-t} \cdot U_{i, \tau}>\frac{1}{2} \cdot\left(\left(\beta_{i} \cdot Y_{i}^{*}\right)^{2}-\left(\beta_{j} \cdot Y_{j}^{*}+x\right)^{2}\right) .
\end{gathered}
$$

Because of it is well possible that the stablest country has an incentive to take part in EMU even if joining EMU is expected to cause negative welfare effects for this country. Ceteris paribus this is the more likely to happen for large $x$-values or high discount rates $r$ (i.e. high rates of time preference). The same is true if the time until EMU will be realized is quite long (i.e. for increasing $\tau-t$ ). For $U_{i}>0$ country $i$ will always take part in EMU. The stablest country fulfilling the above

\footnotetext{
${ }^{29}$ Since the country's loss is increasing in the inflationary bias it will choose the lowest inflation rate that allows country $i$ to choose the outside-option.
} 
condition of participation will be the reference country.

However, the situation gets much easier if a country can choose the outside option by withdrawing from the MT. In that case country $i$ would choose the same inflation rate as in the case of taking part in EMU. It will join EMU if $U_{i}>0$, then.

\section{The decision for "intermediate" countries}

For intermediate countries, i.e. those countries which would have fulfilled condition 11 even without the MT, the situation is similar to the one of the stablest country. An intermediate country $k$ will take part in EMU if

$$
\begin{gathered}
\frac{1}{2} \cdot\left(\beta_{k} \cdot Y_{k}^{*}\right)^{2}+\frac{1}{2} \cdot \beta_{k} \cdot Y_{k}^{* 2}-\left(\frac{1}{1+r}\right)^{\tau-t} \cdot U_{k, \tau}<\frac{1}{2} \cdot\left(\beta_{j} \cdot Y_{j}^{*}+x\right)^{2}+\frac{1}{2} \cdot \beta_{k} \cdot Y_{k}^{* 2} \\
\Leftrightarrow\left(\frac{1}{1+r}\right)^{\tau-t} \cdot U_{k, \tau}>\frac{1}{2} \cdot\left(\left(\beta_{k} \cdot Y_{k}^{*}\right)^{2}-\left(\beta_{j} \cdot Y_{j}^{*}+x\right)^{2}\right) .
\end{gathered}
$$

Because of $\beta_{k} \cdot Y_{k}^{*}<\beta_{j} \cdot Y_{j}^{*}+x$ it is again possible that an intermediate country chooses to join EMU although the country expects negative welfare effects from doing so. As the stable countries, they will do so only if they can not use an outside option.

\section{E. The decision for "unstable" countries}

Unstable countries $l$, i.e. countries for which condition 11 is restrictive when taking part in EMU, will join EMU and thus fulfill the inflation criterion if

$$
\begin{gathered}
\frac{1}{2} \cdot\left(\beta_{j} \cdot Y_{j}^{*}+x\right)^{2}+\frac{1}{2} \cdot \beta_{l} \cdot Y_{l}^{* 2}-\left(\frac{1}{1+r}\right)^{\tau-t} \cdot U_{l, \tau}<\frac{1}{2} \cdot\left(\beta_{l} \cdot Y_{l}^{*}\right)^{2}+\frac{1}{2} \cdot \beta_{l} \cdot Y_{j}^{* 2} \\
\Leftrightarrow\left(\frac{1}{1+r}\right)^{\tau-t} \cdot U_{l, \tau}>\frac{1}{2} \cdot\left(\left(\beta_{j} \cdot Y_{j}^{*}+x\right)^{2}-\left(\beta_{l} \cdot Y_{l}^{*}\right)^{2}\right) .
\end{gathered}
$$

As is true for the other countries, unstable countries will always take part in EMU if the country expects positive welfare effects of EMU.

Because of $\beta_{j} \cdot Y_{j}^{*}+x<\beta_{l} \cdot Y_{l}^{*}$ we can not rule out the possibility that an unstable country takes part in EMU in spite of negative expected welfare effects, again. In contrast to stable or intermediate countries, the incentive to take part in EMU results from the possibility to bring down inflation in stage II of EMU, here. 


\section{F. Conclusions}

Summarizing the above considerations we can state that for the case of the simplified version of the inflation criterion the inflation rates of at least those EU-memberstates, expecting welfare gains by joining EMU, should converge against the inflation rate of the most stable country. This result does only change slightly if we take into account that the inflation criterion in fact has been a little bit more complex than it was assumed in the above analysis. This is easy to see if we assume, for simplicity, that all EU-member-countries expected welfare gains by taking part in EMU. In this case the three countries with the lowest inflation set the standard for the less stable countries. The countries with the second- and the thirdlowest inflation rates might loose their incentive to decrease their inflation rates now, provided they were not intermediate countries in the sense of the above analysis. If the inflation rates of three reference countries differ, the inflation criterion is somewhat less restricting. This might cause some more countries to switch from the group of the former non-stable-countries to the intermediate countries. In the end inflation will still converge, but on a somewhat higher level than under the above considered simplified version of the inflation criterion. Thus, we should find a lower or no negative correlation at all between central bank independence and the inflation rate during stage III of EMU. To test for this hypothesis, we analyze inflation rates in the EU-member-countries, which tried to qualify for EMU, ${ }^{30}$ during the transitional phase to EMU (1992-1998).

Again we start with the Grilli-index and run the following linear multiple regression (OLS method):

$$
\bar{\pi}_{i}=c+\gamma_{1} \cdot I_{i}^{p}+\gamma_{2} \cdot I_{i}^{e}+\varepsilon_{i},
$$

where $\bar{\pi}$ is the average inflation rate, $c$ is a constant, $\gamma_{1}$ and $\gamma_{2}$ are the regression coefficients for the two dimensions of central bank independence, $i$ is a country index and $\varepsilon$ is the residual. For the transitional period we should not find significant coefficients for the measures of central bank independence or at least lower values for $\gamma_{1}$ and $\gamma_{2}$ than in the pre-transitional phase. The results are reported in Table 3.

\footnotetext{
${ }^{30}$ We excluded Denmark, Great Britain and Sweden from the sample since these countries decided not to take part in EMU in 1999.
} 
Table 3. Multiple regression results under the Grilli-index 1992-1998:

\begin{tabular}{cccccc}
\hline Period & $\mathrm{c}$ & $\gamma_{1}$ & $\gamma_{2}$ & Observations & $R^{2}$ \\
\hline \multirow{2}{*}{$1992-1998$} & 6,58 & $-0,18$ & $-0,59$ & 10 & 0,37 \\
& $(3,91)$ & $(-0,39)$ & $(-1,44)$ & & \\
\hline
\end{tabular}

In fact, both coefficients are insignificant and lower than in the pre-transitional period. In addition to that, the estimated regression function explains only one third of the observed average inflation rates in EU-member-countries during the first five years of the transitional phase.

For the Cukierman-index we estimate the following regression-function:

$$
\bar{\pi}_{i}=c+\gamma \cdot I_{i}^{c}+\varepsilon_{i},
$$

The results for the Cukierman-index are reported in Table 4.

Table 4. Regression results under the Cukierman-index 1992-1998

\begin{tabular}{ccccc}
\hline Period & $\mathrm{c}$ & $\gamma$ & Observations & $R^{2}$ \\
\hline \multirow{2}{*}{$1992-1998$} & 3,02 & $\begin{array}{c}-1,41 \\
(-0,88)\end{array}$ & 10 & 0,09 \\
\hline
\end{tabular}

The results are similar to those under consideration of the Grilli-index. Again the coefficient for central bank independence $\gamma$ is insignificant for the transitional period.

Summing up, the empirical data are supportive of the hypothesis that the incorporation of the inflation criterion into the MT contributed to lowering the inflationary bias compared to an unconditional MT.

\section{Summary of Results}

So far welfare effects during the transitional period of EMU have been neglected in the discussion on the convergence criteria. The inflation criterion can be interpreted as an element of an incentive compatible contract. Being part of the MT it enabled national central banks to ensure that there is only a comparatively low rate of inflation. Had the inflation criterion not been included, the national central banks would have had a strong temptation to pursue a monetary policy in the last periods in commission of high employment. The outcome would have been a 
higher rate of inflation but no decrease in unemployment. These arguments are in line with the presented empirical findings.

Received 12 April 2004, Accepted 21 December 2004

\section{References}

Artis, M. J., 1994, European Monetary Union. In: M. J. Artis and N. Lee (Eds.), The Economics of the European Monetary Union. Policy and Analysis (Oxford University Press, Oxford), 346-367.

Barro, R. J. and D. B. Gordon, 1983a, A Positive Theory of Monetary Policy in a Natural Rate Model. Journal of Political Economy 91(4), 589-610.

Barro, R. J. and D. B. Gordon, 1983b, Rules, Discretion and Reputation in a Model of Monetary Policy. Journal of Monetary Economics 12, 101-121.

Berlemann, M. and N. Nenovsky, 2004, Lending of first versus lending of last resort. Lessons from the Bulgarian Financial Crisis 1996/1997. Comparative Economic Studies 46, 245271.

Cukierman, A., 1992, Central bank strategy, credibility, and independence (MIT Press, Cambridge).

De Grauwe, P., 1992, The Economics of Monetary Integration (Oxford).

De Grauwe, P., 1993, The Political Economy of Monetary Union in Europe. World Economy $16,653-661$.

De Grauwe, P., 1996, The Economics of Convergence: Towards Monetary Union in Europe. Weltwirtschaftliches Archiv 132, 1-27.

von Hagen, J., 1995, Inflation and Monetary Targeting in Germany. In: L. Leiderman and L. E. O. Svensson (Eds.), Inflation Target (CEPR, London), 107-121.

von Hagen, J. and M. Fratianni, 1996, Monetary and Fiscal Policy in a European Monetary Union: Some Public Choice Considerations. In: P. J. J. Welfens (Ed.), European Monetary Integration. EMS Developments and International Post-Maastricht Perspectives (Springer, Berlin), 3rd. edition, 275-302.

Heikensten, L., 2000, EMU - cohesion or diversity Speech to the Swedish Institute of International Affairs, Stockholm, 10th November 2000, BIS Review 102, 1-5.

Giavazzi, F. and M. Pagano, 1988, The Advantage of Tying One's Hands: EMS Discipline and Central Bank Credibility. European Economic Review 32, 1055-1082.

Grilli, V., D. Masciandaro and G. Tabellini, 1991, Political and monetary institutions and the public financial policies in industrial countries. Economic Policy 13, 343-392.

Issing, O., 1997, Die Europäische Zentralbank. Das Problem der Glaubwürdigkeit. In: D. Duwendag (Ed.), Finanzmärkte im Spannungsfeld von Globalisierung, Regulierung und Geldpolitik (Duncker \& Humblodt, Berlin), Schriften des Vereins für Socialpolitik 261, 179-192.

Jensen, H., 1997, Credibility of Optimal Monetary Delegation. American Economic 
Review 87, 911-920.

Lohmann, S., 1992, The Optimal Degree of Commitment: Credibility versus Flexibility. American Economic Review 82, 273-286.

McCallum, B. T., 1995, Two Fallacies Concerning Central-Bank Independence. American Economic Review 85, Papers and Proceedings, 207-211.

Rogoff, K., 1985, The Optimal Degree of Commitment to an Intermediate Monetary Target. Quarterly Journal of Economics 100, 1169-1190.

Vaubel, R., 1994, The Public Choice Analysis of European Integration: A Survey. European Journal of Political Economy 10, 227-249.

Wagner, H., 1995, Europäische Wirtschaftspolitik (Springer, Berlin).

Wagner, H., 2001, Preconditions for the Success of the European Monetary Union. In: M. Haller (Ed.), The Making of European Union (Springer, Berlin), 43-65.

Walsh, C. E., 1995, Is New Zealand's Reserve Bank Act of 1989 an Optimal Central Bank Contract? Journal of Money, Credit and Banking 27, 1179-1191.

Walsh, C. E., 2000, Monetary Theory and Policy (MIT Press, Cambridge).

Welfens, P. J. J., 1996a, European Monetary Union: Post-Maastricht Perspectives on Monetary and Real Integration in Europe In: P. J. J. Welfens (Ed.), European Monetary Integration. EMS Developments and International Post-Maastricht Perspectives (Springer, Berlin), 3rd. edition, 1-47.

Welfens, P. J. J., 1996b, Creating a European Central Bank after 1992: Issues of EC Monetary Integration and Problems of InstitutionalInnovation. In: P. J. J. Welfens (Ed.), European Monetary Integration. EMS Developments and International PostMaastricht Perspectives (Springer, Berlin), 3rd. edition, 223-296.

Willms, M., 1996, German Monetary Unification and European Monetary Union: Theoretical Issues and Strategic Policy Problems. In: P. J. J. Welfens (Ed.), European Monetary Integration. EMS Developments and International Post-Maastricht Perspectives (Springer, Berlin), 3rd. edition, 133-157.

Winkler, B., 1999, Is Maastricht a Good Contract? Journal of Common Market Studies 37, 39-58. 